\title{
Harnessing Knowledge for Institutional Advancement in Tertiary Educational Institutions
}

\author{
Ahmed M. Musa \\ University of Education, Winneba, Kumasi Campus, Department of \\ Management Studies, P O Box 1277, Kumasi, Ghana. \\ Email:asemdanipaso3@yahoo.com
}

\begin{abstract}
The impact of globalization on tertiary educational institutions (TEIs) in Ghana demands that they (TEIs) harness and leverage knowledge from the global knowledge basket to remain competitive. This paper examines the concept of knowledge management (KM) and how it is being managed in Ghana's TEIs for institutional advancement. The key challenges identified include the corporatisation of academic faculties, weak structures for KM, the intrusion of 'managerialism' as a style of leadership, absence of strong teamwork in knowledge creation and dissemination, and the erosion of the spirit of collegiality in academic staff relations. Suggestions made for the enhancement of knowledge management processes in TEIs include making adequate budgetary allocations for $\mathrm{KM}$ and integrating $\mathrm{KM}$ centres in established structures of TEIs. The paper concludes that knowledge is an indispensable asset for institutional advancement in higher education and therefore, TEIs should invest in the area to remain competitive globally.
\end{abstract}

Keywords: Knowledge management; Intellectual capital; Managerialism; Institutional governance

\section{Introduction}

A tertiary educational institution (TEI) in Ghana is defined by section 26 of the National Accreditation Board Act, 2007 (Act 744) as institutions of learning that provide post secondary education aimed at awarding Degrees, Diplomas and Certificates. These include universities training colleges, technological institutes and professional bodies.

Knowledge Management (KM) has now entered the lexicon of higher educational institutions as a result of globalization. The competitiveness of TEIs in the comity of nations is determined by the degree of knowledge acquired, created, shared, and utilized for the benefit of humanity (Ray, 2008; Messinghan, 2010; Bijaya \& Uday, 2011). Invariably, the standard and quality of tertiary education proffered by a nation is dictated by its reservoir of intellectual capital (IC) derived from knowledge management. For a tertiary institution to remain competitive and be recognized internationally, it needs to revisit its knowledge creation, acquisition and dissemination strategies to "align them with fundamental shifts in social, cultural, political and technological" developments (Elkin, Devjee \& Farmsworth, 2005; Sandhawalia \& Dalcher, 2011). The prismatic nature of administrative processes in Ghana influences the smooth transition from the traditional ways of delivering higher education to the emerging e-based networks of servicing tertiary education. This has led to gaps between costs, standards of education and access to tertiary education. The provision of quality education is inextricably linked to the availability of resources for knowledge creation, dissemination and utilization. These challenges have been exacerbated by the "internationalization" of tertiary institutions. Von Krogh has argued that high-ranked officers in organizations should act as enablers for knowledge creation (as cited in Jakubit, 2011) because knowledge creation enhances organizational transformative learning and competitiveness. Thus, TEIs reflect on the insight and make conscious decisions to act on exigencies (Jakubit, 2011). Elkin, Devjee and Farmsworth (2005) have indicated that as a result of the emerging integration of the global market place, TEIs need to produce competent graduates who will fit into the multicultural global economy. The implication of these statements on Ghana's TEIs is enormous. The governance frameworks of TEIs influence knowledge creation, acquisition, sharing and dissemination. The institution of inappropriate governance mechanisms in TEIs invariably affects the quality of education. This paper uses theories of $\mathrm{KM}$ and experiences elsewhere to examine challenges facing Ghana's TEIs in their implementation of KM. 


\subsection{Objectives of the paper}

The paper looks at the theoretical underpinnings for managing knowledge in order to remain competitive in a globalized world of higher education. It also examines the institutional frameworks and environmental factors that militate against $\mathrm{KM}$ processes in Ghanaian TEIs. It outlines benefits that could accrue from the adoption of $\mathrm{KM}$ as a strategic choice. The paper concludes by suggesting measures that should be put in place to enhance KM processes for institutional advancement in Ghanaian tertiary institutions. The paper draws the attention of policy makers at the national and institutional level to the essence of $\mathrm{KM}$ in Ghanaian TEIs. It has policy significance for other corporate bodies that need continuous institutional renewal in relation to product development, service delivery and marketing orientation in order for them to remain competitive.

\section{An overview of institutional frameworks for growing KM in Ghana's TEIs}

TEIs in Ghana share similar organizational frameworks through which KM processes evolve. Their institutional framework for harnessing knowledge is predicated on statutory laws, statutes, organizational structures, cultural practices, value systems and management styles. These impose strictures on their efforts to evolve knowledge management strategies.

Okunoye and Rarsten (2003) contended that subSaharan African TEIs have trailed their European counterparts in knowledge creation because of lack of resources and this has led to falling standards in scientific research. This position is supported by Arunachaiam (as cited in Okunoye and Rarsten, (ibid) who indicated that the least developed countries of the world have now been classified as "information have-nots".

For KM to flourish in TEIs, its constituents must be able to make sense of the information they receive from the structures created for the dissemination of information. KM thrives in organizations that leverage freedom as a policy for the sharing of information. Junnarkar has intimated that "organizations are not constrained by information; they are constrained by sense making" (as cited in McShane \& Glinow, 2000). Wexler has indicated however, that it is not easy to map knowledge in heavily structured organizations like universities where members compete for positions, status, authority and power (as cited in Tippins, 2003). According to Tippins (ibid) knowledge mapping enables organizations to "gain insights about what areas of an organization's knowledge base are relevant, obsolete or deficient”. Good institutional governance systems enhance KM programmes by helping to create, map, benchmark and manage knowledge for advancement. TEIs are always in a state of flux, because faculty members may leave in search of better job opportunities or may retire from active service. If efforts are not made to capture the knowledge that they have, they go with it. In most of Ghana's TEIs however, conscious efforts at mapping and retaining knowledge for effective use have not been institutionalized.

\subsection{The essence of knowledge management in TEIs}

Knowledge, according to Tippins (2003) is "information that is relevant, actionable linked to meaningful behaviour and is characterized by its tacit elements that are derived from firsthand experience". $\mathrm{KM}$ involves any structured process or system that enhances an organization's ability to create, acquire, upgrade, share and apply knowledge (Bijaya \& Uday, 2011). According to Ray (2008), KM applications include the placement of enablers that enhance document collaboration, use of data mining tools, data warehousing and databases. An effective KM system in a tertiary institution will be able to locate cross-functional knowledge in various faculties, departments and business units (Honeycutt, as cited in Ray, 2008). The essence of $\mathrm{KM}$ in TEIs is to facilitate the use of critical information for decision making. This invariably includes integrating important corporate information from files, folders, e-mails, intranet and other applications. Honeycutt posits that at the global market place $\mathrm{KM}$ enable organizations to leverage the knowledge of their employees, engage in collaborative networks over long distances and facilitate decision making in real time.

Tertiary institutions sharpen their competiveness and their ability to innovate and respond to fast changing stakeholder expectations through the application of system-oriented knowledge transfer mechanisms. These include decision support systems, artificial intelligence applications, expert systems and artificial neural networks (Metaxiotis, Ergazakis, Samouilidis \& Psarras, 2003; Sandhawalia \& Dalcher, 2011). In the same vein, blended learning - which is "an amalgam of conventional face-to-face (f-2- $\mathrm{f}$ ) interation and e-learning" (Sharma, Pandit \& Pandit, 
2011) can be adopted to create and share knowledge in a tertiary institution.

Rickard (1995) contends that effective KM enables "corporate renewal, learning and transformation to occur". It follows therefore, that institutional stakeholders derive much from investment made in knowledge creation and dissemination. Without knowledge no organization can survive the dynamics and turbulence of the globalized world in the 21st century (Gallivan, Eynon \& Rai, 2002; Ray, 2008; Coulson-Thomas, 1998; Rickard, 1995; McShane \& Glinow, 2000). Similarly, Juma (2007) maintains that reform in tertiary educational curricula should be followed by "adjustment in knowledge to enhance experiential learning”. Knowledge therefore, is the pivot around which higher educational institutions in a developing country like Ghana can survive.

\subsection{Intellectual Capital (IC) and KM processes in TEIs}

A TEIs intellectual capital (IC) should be the basis for rolling out its knowledge management processes (Tippins, 2003). The KM processes in tertiary institutions involve knowledge acquisition, sharing and utilization. The IC in a tertiary educational institution is the totality of the institution's, human, structural and customer capital. It constitutes its "main source of competitive advantage" (McShane \& Glinow, ibid). Therefore, it constitutes a benchmark for assessing a TEIs reputation. A TEIs structural capital involves knowledge systematically captured and stored in its systems and network of structures. The customer capital of an institution constitutes the level of satisfaction that is gained by its clientele customers, suppliers and end-users of its goods and services. TEIs acquire knowledge through individual learning, environmental scanning, grafting and experiments. Individuals in organizations learn through personal experiences, observations, feedback and reinforcement. Environmental scanning relates to the knowledge that TEIs extract from their internal and external environments to enable prudent decisions to be taken and implemented strategically. Grafting involves the acquisition of knowledge by hiring or acquiring the services of individuals who have technical expertise e.g. Professors and Senior Lecturers. Otherwise, resources of other higher educational institutions or research based organizations may be bought, acquired or leased for knowledge generation and dissemination. This engenders cross-fertilization of ideas.
Experiments provide a platform for using internal creativity and experimentation to generate knowledge for use. It is only when knowledge is shared that it can be utilized for institutional advancement and therefore, has value. TEIs that expend resources to acquire knowledge but fail to put in place mechanisms for the knowledge generated to be shared place no value on them. Strategies for sharing knowledge across TEIs and between individuals include formal and informal training systems, internal and external communication processes, team work, and communities of practice in research, conferences, workshops and seminars. TEIs can also share knowledge through information technology based systems like shared intranet portals that "act as a window to an organization's specialized knowledge repositories" (Taminau, Y., Wouter, S., de Lange, A., 2009).

In TEIs knowledge utilization is at the core of their survival. Information acquired through knowledge is used to re-engineer existing ways of doing things and to re-align institutional work processes. Knowledge is also used to socialize and improve cultural processes in TEIs to refocus and enhance the achievement of service deliverables.

\section{Challenges militating against $\mathrm{KM}$ processes in Ghanaian TEIs}

The implementation of KM programmes in Ghana's TEIs has been constrained by several factors. Mullins (1999) has intimated that intellectual property rights remain a thorny issue in KM because companies are continuously outsourcing knowledge from universities. This has implications for TEIs in Ghana. Whereas researchers want to publish their findings for the reading public and for promotion, sponsoring organizations and TEIs in Ghana want them as part of their IC. Invariably, the confusion between TEIs, researchers and other organizations inhibit the sharing and utilization of the knowledge acquired. This incidence has been emphasized by McBrierty \& Kinsella (1997). An effective KM system thrives on the support given by management (Ray, 2008). Unfortunately, this has not always been the case in TEIs and this inhibits knowledge creation, dissemination and usage. Often research findings end up on shelves due to absence of administrative will to utilize them. This is often exacerbated by poor intraorganizational communication systems and structures, i.e. bottom-up, top-down, lateral and diagonal information flow has often constrained KM processes. 
A TEIs ability to acquire and share knowledge is dependent upon the competencies of its academic faculty. Therefore, persons appointed to Lectureship, Headship and Deanship positions in TEIs necessarily belong to those faculties of knowledge because higher educational institutions are knowledge intensive organizations where heads should be able to lead academic scholarship (Nelson, 1990). Tertiary educational institutions unlike other corporate organizations are built on silos or canons of knowledge. These are cross-fertilized through interfaculty and interdisciplinary knowledge creation, sharing and utilization.

In recent times the concept of "managerialism" has gained currency in higher educational institutions in Ghana. Managerialism as a style of management has been borrowed from the non-academic corporate world for higher educational management. It is a process whereby managers play intrusive role in determining what should and should not be implemented in service or product delivery (Reid, 1998; Pollit, 1990). Since TEIs are knowledge intensive organizations is managerialism an ideal system of management for a developing country like Ghana? Pollit (ibid) further contends that managerialism is focused on control and financial mechanisms and not with planning and organizational structures - a major weakness of the concept.

Proponents of managerialism in Ghanaian higher educational management believe that faculties and departments share similarities than differences, and as a result of this, corporate strategic objectives can be achieved by the application of generic management competencies, skills and theory acquired elsewhere. Therefore, even though TEIs are knowledge intensive organizations, "corporate" Deans, and Heads are imposed to "manage" academic faculties and departments. Deans and Heads appointed on these premises in TEIs, lack academic legitimacy because they do not exercise expert and referent power -core credentials in academic faculty placement. They also lack explicit and tacit knowledge (McShane \& Glinow, 2000). Harman (2002) has stated that Australian TEIs are moving from the traditional collegial system of management to the corporate style. This according to him has shifted the loyalty of Deans and Heads to Vice-chancellors instead of their departmental and faculty constituents. This academic construct which is being replicated in Ghana's TEIs militates against $\mathrm{KM}$ processes because the culture, value systems, structure, internal dynamics, in TEIs are completely different from those of non- educational corporate bodies like banks, mining companies, trading enterprises or manufacturing concerns. Therefore, there is the need for a person-job fit in the appointment of persons to headship positions in TEIs.

The team effort for harnessing knowledge for institutional advancement is lost when faculty realizes that their heads lack academic credibility e.g. where a person with a background in English literature is imposed as the Dean or Head of a Business faculty. In the non-academic corporate world, conscious efforts are made to systematically train would be managers in all aspects of management i.e. planning, controlling, directing, forecasting, organizing, etc. This organizational culture is rare in Ghanaian (TEIs) where appointment to headship and managerial positions is tied to Senior Lectureship or Professorial ranks. The blanket application of generic management competencies and skills to tertiary educational management in some Ghanaian TEIs leads to resentment and frustration amongst faculty and this frustrate the Knowledge creation, sharing and utilization processes.

The knowledge developed by faculties and departments should reflect their departmental corporate strategic objectives. Faculty members are therefore, promoted on these benchmarks. The faculty for a medical school for example, should necessarily reach into medical and allied health sciences research; schools of engineering should have a focus on engineering knowledge and research; Some TEIs accept research papers that are not "faculty specific" for the promotion of lecturers. It is therefore, possible to have senior faculty who have not made any meaningful contribution to knowledge in their areas of study. Even though collaborative writing is encouraged in TEIs this is often abused when effective measures are not put in place to prevent fraudulent practices. An example could be where a lecturer in chemistry publishes a joint article in English literature with a colleague in the English Department. Where a chemistry faculty is promoted or appointed to senior positions on such basis, s/he adds no value to the knowledge management process. These are common practices in some Ghanaian TEIs. The knowledge that the Faculty or Department creates in such circumstances are disoriented.

Organizational socialization provides a platform for employees to learn about their firm's culture and share the values with others (Moorhead \& Griffin, 1995). Socialization strategies include orientation programmes, get-togethers, durbars, seminars, workshops and club-house face-to-face interactions. 
These instruments help build strong bonds of unity and energize the collegial spirit in TEIs thereby, facilitating the sharing and utilization of knowledge outside the traditional media of knowledge sharing and dissemination. Unfortunately, persons holding senior positions in academia often distance themselves from other faculty members thereby creating a "we" and "them" organizational system that does not promote fruitful interaction between faculty members outside the traditional structures of communication. There are often deep divisions amongst staff at faculty and departmental levels thereby curtailing prospects for knowledge sharing outside the traditional lines and structures of communication. According to McShane \& Glinow, (2000), teams are replacing individuals as the building blocks of organizations. Team enabled Faculties or Departments create, share and utilize knowledge in real-time as people are encouraged to work collegially and to coordinate work activities amongst themselves to achieve set goals or objectives (Sisaye, \& Palubo, 2005a). The institution of best "worker" or "lecturer" award as a deliberate projection of individuals in work-related schemes in TEIs discourage teamwork in Ghanaian TEIs. As more and more lecturers aspire to catch the eye of senior officers for awards in academia, the desire to share knowledge acquired is put on ice. Persons desirous of winning awards refuse to share their knowledge readily for fear of losing their clout. Insufficient budgetary allocation to faculties and departments for conferences, workshops and seminars also hinder the development of knowledge based programmes. The bureaucratic stricture one has to overcome to acquire, share or utilize knowledge is sometimes enormous and this inhibits KM.

TEIs are made up of people from diverse political, social and cultural backgrounds. In structured organizations of this magnitude, conflict enablers are common. Stereotyping, perceptual biases and issues involving social identity cast dark shadows on working relations. These militate against knowledge development and dissemination. Karsten and Okunoye (2003) have indicated that researchers in other parts of the world have leveraged benefits derived from the use of computers to the full and this has led to the proliferation of relevant knowledge for development. The use of intranet and internet facilities for knowledge development and dissemination in Ghanaian TEIs is at the developmental stages.

\section{The way forward}

Knowledge is the pivot around which Ghana's TEIs survive. They can only survive global competition for the supply of skilled and competent graduates if $\mathrm{KM}$ is taken seriously. The governance systems in Tertiary institutions must be overhauled to remove administrative bottlenecks that tend to impede the acquisition, sharing and utilization of knowledge. In this vein, KM centres should be integrated into the established structures of TEIs so that knowledge can be managed efficiently. Kistan (2005) has indicated that the challenges and deficiencies faced by tertiary institutions in South Africa are the direct consequences of "fragmented, inefficient and ineffective" governance systems in place. Adequate financial and material resources must be allocated for knowledge management programmes. The move from collegial to corporate styles of educational management should be reexamined in Ghana's TEIs because models that have been successful in developed countries may not work in the Ghanaian context. Where possible, TEIs in Ghana should outsource qualified persons from sister institutions or abroad to fill gaps in their Faculties and Departments. To reduce tension and bad blood between people and enhance we-feeling, diversity management programmes should be implemented in TEIs.

Institutional drawbacks woven around bureaucracy and red-tape must be relaxed to allow for easy acquisition and implementation of knowledge. Knowledge mapping and organizational memory strategies should be instituted in TEIs to create reservoirs of knowledge that can be readily tapped, shared and utilized across board especially through on-line services. Kistan (ibid) intimated that there is a chronic mismatch between the outputs of South African tertiary education and the needs of a modernizing economy. The challenges raised by Kistan have semblance in Ghana's TEIs. To ensure that knowledge acquired in tertiary institutions is relevant to the needs of the nation, ICT facilities should be improved and properly managed to enhance KM.

\section{Conclusions}

Little research has been conducted on KM processes in Ghanaian TEIs. Research conducted elsewhere has been used in this paper as a common denominator to 
stress the essence of KM systems in Ghana's tertiary institutions. The advent of globalization and its consequent impact on tertiary institutions have serious implications for TEIs in Ghana. They cannot operate in a box, outside the scrutiny of regulators and international organizations. To remain competitive globally, KM should be taken seriously if Ghanaian TEIs are to make their mark globally. Administrative and cultural strictures that inhibit $\mathrm{KM}$ processes should be removed to foster cooperation and team work. Models of KM processes in developed countries are required to help bridge the gap in knowledge acquisition, sharing and utilization but such models should be contextualized to make them effective.

\section{Reference}

Alavi, M. ,and Leidrer, D.E., (2001). Knowledge Management and Knowledge Management Systems: Conceptual Foundations and Research Issues. MIS Quarterly, Vol.25, No.1,pp. 107-136.

Bijaya, M., and Uday, B., (2011). Knowledge Management Process in Two Learning Organizations. Journal of knowledge Management, Vol.15, No.2, pp. 433-359.

Bukowitz, W.R., and Williams, R.L., (1999). The Knowledge Management Field Book. Pearson Education, London.

Cornelius, P., (2005). Good Corporate Practices in Poor Corporate Governance Systems. Corporate Governance, Vol.5, No.3,pp. 12-33.

Coulson-Thomas, C. ,(1998). Knowledge is Power. Chartered Secretary, January, 24-24

Danleavy, P., Margetts, H., Bastow, S. ,and Tinkler, T., (2005). The New Public Administration is Dead Long Live Digital-Era Governance. Oxford University Press, London.

Davenport, J. H., Jarvenpaa, S., and Beers, M. ,(1996). Improving Knowledge Work Processes. Sloan Management Review, Vol.37, No.4,pp. 53-65.

Elkin, G., Devjee, F., and Farmsworth, J., (2005).Visualizing the Internationalization of Universities. International Journal of Educational Management, Vol.19, No.4,pp.318-329.

Faucher, P. L., Lawson, B. J., Everall, A. M ., and Lawson, R.,(2008). Reconstituting Knowledge Management. Journal ofknowledge Management, Vol.12, No.3,pp. 316.
Gallivan, M.J., Eynon, J., Rai ,A., (2002). The Challenge of Knowledge Management Systems Underlying Performance Improvement Initiatives. Information Technology and People, Vol. 16,No.3,pp. 1326-1352.

Ghana, National Accreditation Board Act, 2007 (Act 744), L.I. 1700.Ghana, National Accreditation Board Act, 2007 (Act 744).

Harman, G., (2002). Academic Leaders or Corporate Managers: Deans and Heads in Australian Higher Education. Higher Education Management and Policy, Vol.14, No.2,pp. 53-70.

Jakubik, M., (2011). Becoming to Know: Shifting the Knowledge Creation Paradigm. Journal of Knowledge Management, Vol.15, No.3,pp. 374-402.

Kistan, C., (2005). Integrating Quality Assurance Systems in a Merged Higher Education Institution. Quality Assurance in Educational, Vol.13, No.3,pp. 241-250.

Massinghan, P., (2010). Knowledge Risk Management: A framework. Journal of Knowledge Management. Vol.14, No.3,pp. 464-485.

McBrierty, V., and Kinsella, R. P., (1997). Intellectual Property in A Knowledge Society - The Role of the Universities. Industry and Higher Education, Vol.11, No.6,pp.341-348.

McShane, S.L., and Glinow, M.A.V., (2000). Organizational Behaviour. McGrawHill, Boston.

Metaxiotis, K., Ergazakin, K., Samouilidis, E., and Psarras, J., (2003). Decision Support through Knowledge Management: The role of Artificial Intelligence, Journal of Information Management and computer Security. Vol.11,No.5, pp.216-221.

Moorhead, G., and Griffin, R.W. ,(1995).Organizational Behaviour: Managing People and Organizations. $\left(4^{\text {th }}\right.$ edition.) Houghton Mifflin Company,Boston.

Mullins, L.J., (1999). Management and Organizational Behaviour ( $5^{\text {th }}$ edition.). Prentice Hall, London.

Nelson, C., (1990). Harvard's Hollow Core. The Atlantic monthly, pp. 70-80.

Okunoye, A. ,and Karsten, H., (2003). Global Access to Knowledge. Information Technology and People, Vol.16, No.3,pp. 353-373. 
Percin, S., (2010). Use of Analytic Network Process, in Selecting Knowledge Management Strategies, Vol.33,No.5,pp. 452-471.

Pollit, C., (1990). Managerialism and the Public Service. Basil Blackwell, Oxford.

Ray, L. L. ,(2008). Requirements for knowledge Management: Business Driving Information Technology. Journal of knowledge management, Vol.12, No.3,pp. 156-168.

Reid, R. P.,(1998). Charter flight. Times higher Education supplement. Management education, Issue 25.

Rickard, J. ,(1995). Learning that is far from Academic. People Management, 9 March.

Sandhawalia, B. S., and Dalcher, D., (2011). Developing Knowledge Management Capabilities: A Structured Approach. Journal of knowledge management, Vol. 11, No.2,pp.313-328.
Sharma, K., Pandit, P., and Pandit, P., (2011). Critical Success Factors In Cafting Strategic Architecture for eLearning at HP University. International Journal of Educational Management, Vol. 25, No.5,pp. 423-452.

Sisaye, S. , and Palumbo, A. J., (2005). Management Control Systems and Organizational Development. Journal of Leadership and Organizational Development, Vol.26, No.1, pp.51-61.

Sisaye, S., and Pulambo, A.J., (2005). Team and Management Control Systems: A Synthesis of Three Organizational Development Approaches. Journal of Leadership Development, Vol.26, No.3,pp. 172-185.

Taminau, Y., Wouter, S., and De Lange, A., (2009). Innovation in Management Consulting Firms through Informal Knowledge Sharing. Journal of Knowledge Management, Vol.13, No.1,pp. 42-55. 